\title{
The Brazilian Compound Library (BraCoLi) database: a Brazilian repository of chemical and biological information for drug design
}

Gabriel Corrêa Veríssimo ${ }^{1 *}$, Valtair Severino dos Santos Júnior ${ }^{1 *}$, Ingrid Ariela do Rosário de Almeida1, Marina Sant'Anna Mitraud Ruas, Lukas Galuppo Coutinho $^{1}$, Renata Barbosa de Oliveira ${ }^{1}$, Ricardo José Alves ${ }^{1}$, Vinícius Gonçalves Maltarollo ${ }^{1 \ddagger}$

1. Laboratório de Química Farmacêutica, Departamento de Produtos Farmacêuticos, Faculdade de Farmácia, Universidade Federal de Minas Gerais, Belo Horizonte, Brazil.

*The authors equally contributed to the manuscript

‡Correspondence author: viniciusmaltarollo@gmail.com

\section{ABSTRACT}

The Brazilian Compound Library (BraCoLi) is a novel virtual library of manually curated compounds developed by Brazilian research groups to support further computer-aided drug design works. Herein, the first version of the database is described comprising 1,176 compounds. Also, the chemical diversity and drug-like profile of BraCoLi were defined to analyze its chemical space. A significant amount of the compounds fitted Lipinski and Veber's rules, alongside other drug-likeness properties. Principal component analysis showed that BraCoLi is similar to other databases (FDA-approved drugs and $\mathrm{NuBBE}_{\mathrm{DB}}$ ) regarding structural and physicochemical patterns. Finally, a scaffold analysis showed that BraCoLi presents several privileged chemical skeletons with great diversity.

Keywords: drug design, database, chemical library, medicinal chemistry, cheminformatics.

\section{INTRODUCTION}

The application of computational tools as an ally in drug design was an important milestone in medicinal chemistry. This approach is known as computer-aided drug design (CADD) and it is extensively used in several studies to optimize the discovery and design of new drug candidates ${ }^{1,2}$. Molecular docking, structure-activity relationship 
(SAR) studies, and virtual screening are a few examples of available computational techniques that are widely employed in drug design ${ }^{3}$.

Currently, CADD data comes from several individual works available in the literature or in some websites. These strategies demand a large amount of chemical information to automatize the screening of novel bioactive compounds. Therefore, chemical databases were built as a resource to obtain this type of data $a^{4,5}$. They were architected to store, organize, and enable the search for readily available and quantitative information of biological application, physicochemical, and molecular properties of ligands and targets $^{6,7}$. There are some examples of free-to-access virtual chemical libraries that are extensively used on CAAD nowadays that could be highlighted (Table 1).

Table 1. Open-access databases containing information about small molecules and their biological activities useful for CADD. The databases are shown in descending order of number of compounds. Reported numbers were obtained in March 2021.

\begin{tabular}{lclc}
\hline \multicolumn{1}{c}{ Database } & Entries & \multicolumn{1}{c}{ Link } & Reference \\
\hline ZINC & $230 \mathrm{M}$ & $\underline{\text { http://zinc20.docking.org/ }}$ & {$[8]$} \\
PubChem & $100 \mathrm{M}$ & $\underline{\text { https://pubchem.ncbi.nlm.nih.gov/ }}$ & {$[9]$} \\
ChEMBL & $2.1 \mathrm{M}$ & $\underline{\text { https://www.ebi.ac.uk/chembl/ }}$ & {$[10,11]$} \\
BindingDB & $971 \mathrm{~K}$ & $\underline{\text { https://www.bindingdb.org/bind/index.jsp }}$ & {$[12]$} \\
TCM Database & $37 \mathrm{~K}$ & $\underline{\text { http://tcm.cmu.edu.tw/about01.php?menuid=1 }}$ & {$[13]$} \\
DrugBank & $15 \mathrm{~K}$ & $\underline{\text { https://go.drugbank.com/ }}$ & {$[14]$} \\
Drug Repurposing Hub & $6.9 \mathrm{~K}$ & $\underline{\text { https://clue.io/repurposing }}$ & {$[15]$} \\
NuBBEDB & $2.2 \mathrm{~K}$ & $\underline{\text { https://nubbe.iq.unesp.br/ }}$ & {$[16,17]$} \\
AntibioticDB & $1 \mathrm{~K}$ & $\underline{\text { https://www.antibioticdb.com/ }}$ & {$[18]$} \\
AfroDB & 954 & $\underline{\text { http://zinc.docking.org/catalogs/afronp/ }}$ & {$[19]$} \\
BIOFACQUIM & 421 & $\underline{\text { https://biofacquim.herokuapp.com/ }}$ & {$[20]$} \\
\hline
\end{tabular}

Thus, the process of building libraries is critical since the data must be diverse and reliable to enable safe chemoinformatic experiments, being crucial in the scenario of designing new drugs ${ }^{21}$. It is important to emphasize that in silico approaches help and speed up the search for new bioactive compounds. This can reduce the amount of compounds to be tested in in vitro and in vivo assays, anticipating adequate pharmacokinetic profiles, high selectivity, and low toxicity predictions ${ }^{22,23}$. In this way, virtual libraries contribute to increase the success rate in the process of selecting new leads, gathering information with parsimony, ensuring the quality, variety, and consistency of the curated data ${ }^{2,21,24}$. 
Inspired by these examples, the Brazilian Compound Library (BraCoLi) was built as a manually curated and open-access database containing biological and chemical information of synthetic and natural semisynthetic molecules from Brazilian research groups. In this work, a description and a cheminformatic characterization of BraCoLi based on chemical features and drug-like profiling, comparing with other databases is presented. The comparison was based on molecular, pharmaceutical, and physicochemical properties of interest in drug design. The data was initially compilated from our research group on Pharmaceutical and Medicinal Chemistry from the Universidade Federal de Minas Gerais (UFMG, the Federal University of Minas Gerais), encouraging us to provide the dataset to the scientific community.

\section{RESULTS AND DISCUSSION}

\section{Description of BraCoLi database and biological applications}

To compose the first version of the BraCoLi database, 31 peer-reviewed thesis and papers that evaluated any biological activity of pure and characterized compounds from our research group were analyzed. In this sense, 1,176 unique compounds derived from natural scaffolds and completely synthetic compounds were gathered. For each entry, the molecular formula, molecular weight, melting points and, when available, biological information were reported. The structures are displayed in 3D lowest energy conformers and are available in mol2 and SDF file formats. In addition, XLSX and PDF files with chemical and biological information regarding the compounds are also provided. All files are available for download at https://www.farmacia.ufmg.br/qf/downloads/.

The substances showed a broad range of activity, with reported antibacterial, antifungal, antileishmanial, antimalarial, antioxidant, antitrypanosomal, antiviral, and cytotoxic activities. From BraCoLi database, two classes of compounds with great advance in drug development could be highlighted. Firstly, 2-thiazolylhydrazone derivatives (Figure 1) such as RN104 and RI76 have shown promising in vitro and in vivo antifungal potential against both standard strains and clinical isolates of Candida and Cryptococcus species, 25-32. Anti-diabetes and antioxidant activities were also reported for these analogs. These compounds have been evaluated in preclinical assays, including (i) analytical characterization $^{33}$, (ii) in vivo, in vitro and in silico pharmacokinetic and toxicity profiles $^{34,35}$, (iii) stability studies ${ }^{36}$, and (iv) tests with different formulations to improve solubility ${ }^{37}$. 

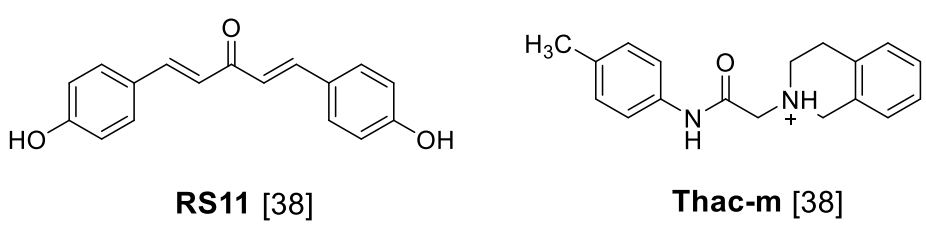

Thac-m [38]

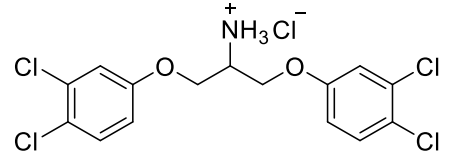

2j [44]

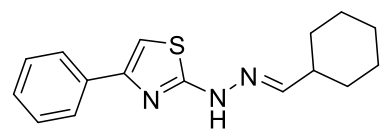

RN104

$[34,35,37]$

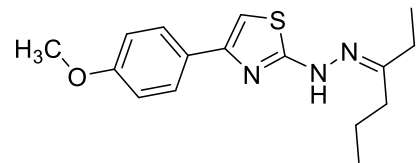

RI76

$[33,36]$

Figure 1. Structures of prominent bioactive compounds from BraCoLi database. Compounds RS11 and Thac-m were selected by Asse Junior et al. (2020) ${ }^{38}$ and presented MIC values of 125-250 $\mu \mathrm{M}$ against $S$. aureus and MRSA strains. 2j, a 1,3bis(aryloxy)propan-2-amine derivative, presented fungicidal activity against Candida spp. in infected Drosophila melanogaster flies. RI17 and RN104 are potent 2thiazolylhydrazone antifungal agents that were evaluated in the beforehand preclinical assays.

Other important set of substances includes the 1,3-bis(aryloxy)propan-2-amines and 1,3bis(aryloxy)propan-2-ols derivatives such as compound 2j (Figure 1) with a broad spectrum of activities. There are reports describing their in vitro antibacterial ${ }^{39}$, antifungal $^{40}$, antileishmanial ${ }^{41,42}$ and antitrypanosomal ${ }^{43}$ activities, as well as a pharmacokinetic and pharmacodynamic characterization in D. melanogaster model of candidiasis $^{44}$ and a patent deposited in Brazil ${ }^{45}$.

In addition, a preliminary unpublished version of the database has been applied to develop new antibacterial leads, exemplifying the application of BraCoLi in cheminformatics. Asse Junior and co-workers (2020) carried out a virtual screening to select potential Enoyl-ACP reductase (Fabl) inhibitors. The authors carried out a ligandbased virtual screening via chemical similarity models using the in-house dataset alongside ZINC, FDA-approved drugs, TCM, and NuBBE $_{D B}$ databases. Four compounds were selected from BraCoLi and 2 of them (Figure 1, RS11 and Thac-m) presented antibacterial activity against standard strains of Staphylococcus aureus and MRSA as well as clinical isolates ${ }^{38}$. 


\section{Chemical space and drug-like profiling of BraCoLi}

The chemical space of BraCoLi database was compared to 750 FDA-approved drugs between 1900 and $2017^{46}$ and 2,223 compounds retrieved from NuBBE $\mathrm{DB}_{\text {in }}$ terms of chemical features and drug-like profiles. Firstly, nine molecular and physicochemical properties aiming to compare their drug-likeness were calculated: molecular weight (MW), logarithm $n$-octanol/water partition-coefficient calculated using the Moriguchi method (MLogP), number of hydrogen bond acceptors (HBA) and donors (HBD), topological polar surface area (TPSA), number of rotatable bonds (nRotB), hybridization ration (HybRatio), number of atoms (nAtoms) and the number of rings (nRings). The drug-like potential of the compounds was analyzed based on two drug-likeness empirical rules: Lipinski's (Ro5) (MlogP $\leq 5, \mathrm{MW} \leq 500 \mathrm{Da}, \mathrm{HBA} \leq 10, \mathrm{HBD} \leq 5)^{47}$ and Veber's rules (TPSA $\leq 140 \AA^{2}$, nRotB $\leq 10$ ) ${ }^{48}$. For the other properties, the value ranges provided by Ghose $(20 \leq \text { nAtoms } \leq 70)^{49}$ and Muegge's (nRings $\left.\leq 7\right)^{50}$ rules were employed as references for drug-likeness. These rules are applied to predict oral bioavailability of substances according to physicochemical fitness to prior stablished ranges for each property.

The compounds presented a remarkably similar Gaussian distribution for MW and MLogP (Figure 2a). These databases present both hydrophilic and hydrophobic compounds $(1<\mathrm{MLogP}<7)$, indicating a moderate solubility in water probability whereas a good absorption in TGI. Most of the molecules (980 entries or $82.98 \%$ for MW and 1,160 entries or $98.22 \%$ for MLogP) fitted the quartile between the maximum values provided by Ro5. The average values for MW and MLogP were 378.58 Da and 2.58, respectively. Still in Ro5 discussion, Figure $\mathbf{2 b}$ shows a high population in the quartile between the adequate ratio of hydrogen-bond acceptors and donors, where 926 compounds (78.40\%) showed no more than $10 \mathrm{HBA}$, and 1,103 (93.40\%) presented no more than 5 HBD. Furthermore, nine hundred compounds $(76.21 \%)$ fitted both conditions. Finally, Figure $\mathbf{2 c}$ represents a comparison between the two Veber's rules: number of rotatable bonds and topological polar surface area. Both parameters are related to the flexibility and capability of penetration in the cell membrane. Most molecules (887 entries or $75.11 \%$ for TPSA and 924 entries or $78.24 \%$ for $n R o t B$ ) fitted the maximum values stablished by Veber and co-workers. The mean value for TPSA was $106.10 \AA^{2}$. Also, nRotB showed an average value of 7.77. The highest densities of points fitted the Lipinski and Veber's rules ranges (MW $<500 \mathrm{Da}, 1<\mathrm{MLog} P<5$, HBA $<10, \mathrm{HBD}<5, \mathrm{nRotB}<10$, TPSA $<140 \AA^{2}$ ). At final count, 862 substances showed no violations and 133 showed one violation to Ro5 (totalizing 995 entries or $84.25 \%$ ), 815 
compounds (69\%) fitted Veber's parameters, and 814 compounds (68.92\%) fitted both empirical rules, showing a proper drug-like profile of the dataset.

(a)
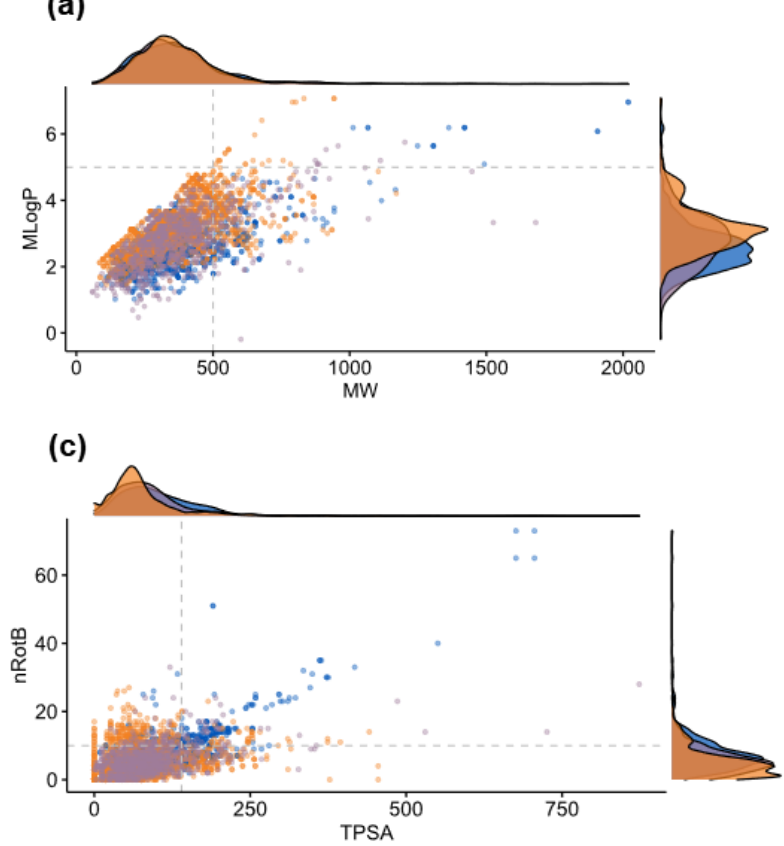

(e)

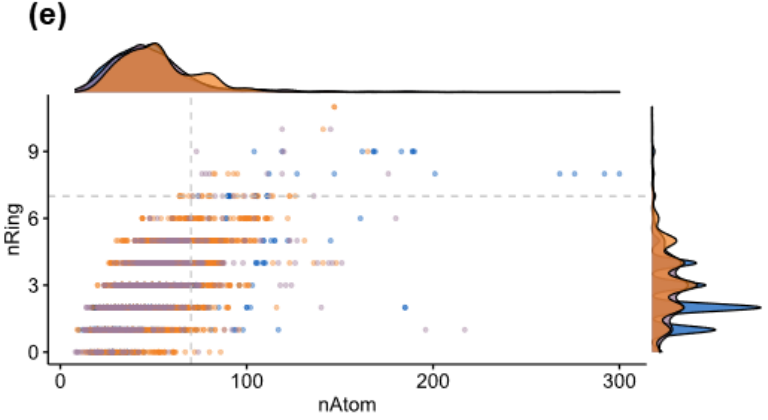

(b)
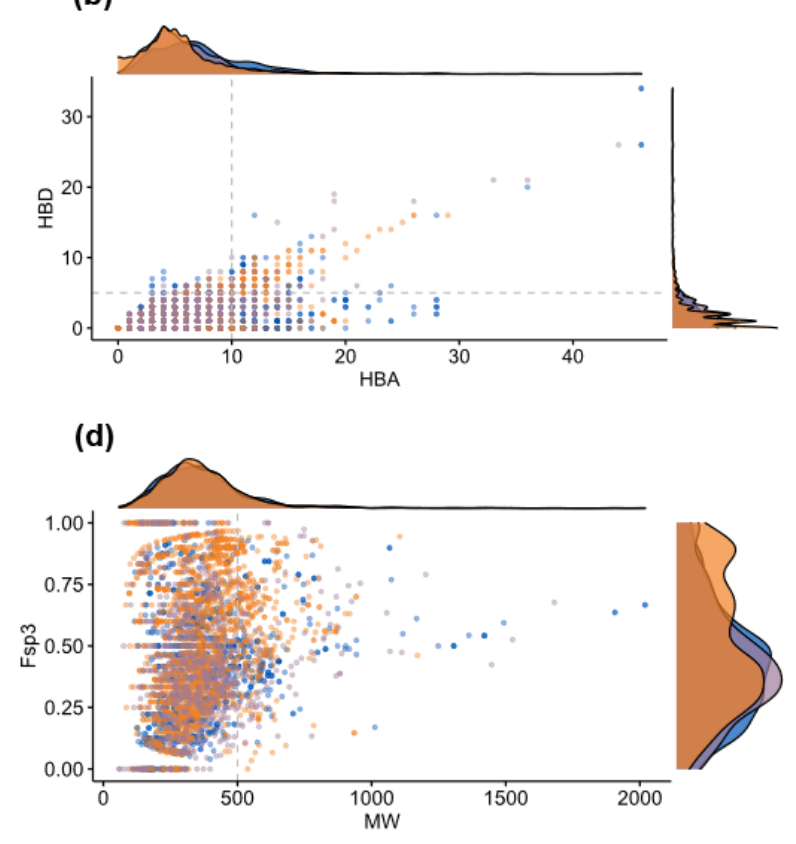

- - - - - Maximum drug-likeness value

BraCoLi

Drugs

Figure 2. Scatter plots of the compounds of the BraCoLi (blue), FDA-approved drugs (orange), and NuBBE $E_{D B}$ (lilac) according to molecular and physicochemical properties of relevance for drug-like profiling. The gray dashed line shows the range of each property according to Lipinski's and Veber's rules. The visual representations are a) MlogP vs MW, b) HBD vs HBA, c) nRotB vs TopoPSA, d) HybRatio vs MW, and e) nRing vs nAtoms.

Further comparisons were carried out to evaluate other physicochemical parameters. Figure $2 \mathbf{d}$ shows the comparison of the fraction of $\mathrm{sp}^{3}$ carbons $\left(\mathrm{Fsp}^{3}\right)$ values to $\mathrm{MW}$. $\mathrm{Fsp}^{3}$ are related to the flexibility of the molecules, such as $\mathrm{nRotB}$. The average value of Fsp ${ }^{3}$ was 0.43 , meaning an approximately $\mathrm{Csp}^{3}$ ratio of $1 / 2.3$, indicating that the dataset contains more rigid than flexible structures. The parameters quantity of atoms (nAtoms) and quantity of rings (nRings) were also compared, as shown in Figure 2e, since these 
properties are related to the size of the molecules. As expected, the parameters presented high correlation to each other. The mean values calculated for nAtoms and nRings were 48.66 atoms and 2.45 rings, fitting the ranges predicted by the empirical rules, and 999 entries (84.59\%) fit both rules simultaneously. It could be seen in all scatter plots from Figure 1, BraCoLi presented similar distributions to FDA-approved drugs and $\mathrm{NuBBE}_{\mathrm{DB}}$ in all comparisons.

The BraCoLi database, FDA-approved drugs, and NuBBE $\mathrm{DB}_{\mathrm{DB}}$ were compared regarding their chemical and structural spaces (Figure 3). The chemical spaces were generated employing principal component analysis (PCA), using two major approaches: (i) druglike profiles in terms of the nine physicochemical properties evaluated beforehand (nAtoms, HBA, HBD, HybRatio, MlogP, MW, nRings, nRotB, TPSA (Figure 3a); and (ii) molecular fingerprints, according to PubChem fingerprints set (Figure $\mathbf{3 b}$ ). Both plots are represented by the first two principal components (PC1 and PC2), where PC1 showed most contribution to the PCA (94.3\% for drug-like-based PCA and $19.2 \%$ for fingerprint-based PCA). All three chemical sets show a similar distribution in the PCA plots, as expected from the drug-likeness analysis, indicating that the compounds present a comparable predicted pharmacokinetic profile. This indicate that, even they represent different datasets, BraCoLi presents an interesting applicability to discover lead candidates with adequate drug-like profiles in comparison to other largely used databases.

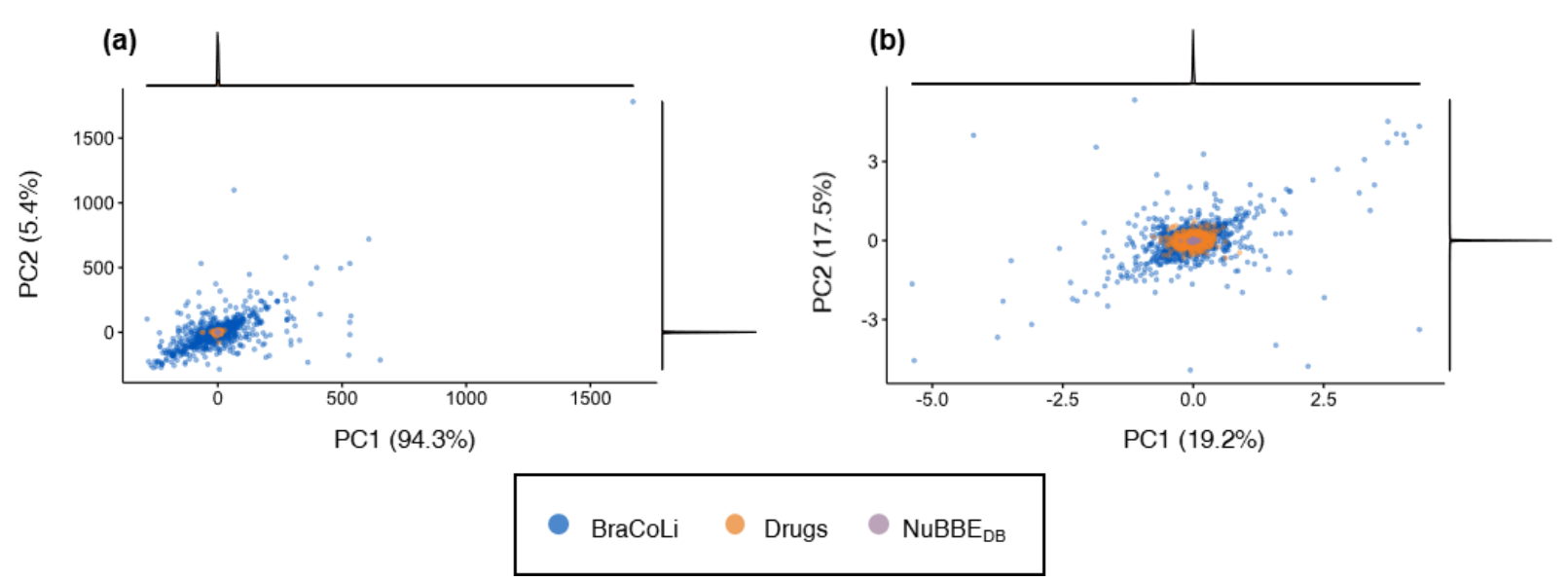

Figure 3. Chemical space visualization for the BraCoLi (blue), FDA-approved drugs (orange), and $\mathrm{NuBBE}_{\mathrm{DB}}$ (lilac) generated by PCA. The comparison based on a) drug-like profiles and $\mathbf{b}$ ) molecular fingerprints. 
Although these drug-likeness rules are still universally applied in the early stages of drug design, it is important to stress that some approved drugs violate them. Even Lipinski (2004) states that some scaffolds do not fit the Ro5 four parameters, especially natural products or derivatives and molecules that are recognized by active transport systems ${ }^{51}$. Pathania and Singh (2020) discuss in an editorial paper when is the ideal stage of drug development to take account on pharmacokinetic optimization and how empirical rules are helpful. According to the authors, 15 out of 26 FDA-approved small molecules in 2020 do not fit one or more drug-likeness rules. They suggest to apply those predictions after the evaluation of biological activity ${ }^{52}$. Other works also accent the necessity to revise those empirical rules after several years and expand the chemical space to fit new bioactive molecules with adequate experimental drug-like profiles ${ }^{53-57}$. Obviously, it is a compelling starting point that two-thirds of BraCoLi database present an adequate druglike prediction, which can facilitate the screening of potential bioactive compounds, but it is necessary to balance both pharmacokinetic and pharmacodynamic profiles, since a molecule with a good pharmacokinetic profile does not necessarily present potent bioactivity and vice-versa ${ }^{52,55}$.

\section{Chemical scaffolds}

To verify the chemical diversity of the dataset, the most frequent scaffolds were analyzed using the DataWarrior software. The twenty most frequent scaffolds are shown in Table 3, which most of them are heterocycles containing oxygen, nitrogen and/or sulfur in 5or 6-membered rings. As discussed by Jampilek (2019), heterocycles are a very versatile group of structures with important applications in medicinal chemistry. Due to their privileged fragments, they present a broad spectrum of bioactivities as well as they can be easily modified or simplified to optimize pharmacodynamic and pharmacokinetic profiles $^{58}$. For instance, the butenolide ring can be highlighted, which presents several biological activities ${ }^{59}$, and being present in digoxin, for example, a drug applied for heart disorders treatment. 
Table 3. Top 20 most frequent chemical scaffolds presented in the BraCoLi database.

\begin{tabular}{|c|c|c|c|c|}
\hline 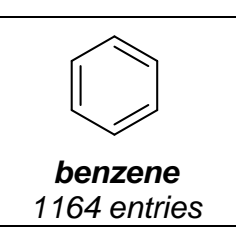 & $\underset{\substack{\text { oxane } \\
455 \text { entries }}}{\square}$ & $\underset{\substack{\mathrm{N} \\
\mathrm{H} \\
\text { oxazolidine } \\
76 \text { entries }}}{\mathrm{O}}$ & $\underbrace{\mathrm{N}=\mathrm{N}}_{\substack{1,2,3-\text { triazole } \\
76 \text { entries }}}$ & $\begin{array}{c}\left.\|_{\mathbf{N}}^{S}\right\rangle \\
\text { 1,3-thiazole } \\
60 \text { entries }\end{array}$ \\
\hline $\begin{array}{c}\text { benzimidazole } \\
50 \text { entries }\end{array}$ & $\overbrace{\substack{\text { Cyclohexanimine } \\
46 \text { entries }}}^{\mathrm{NH}}$ & $\begin{array}{c}\text { oxole } \\
44 \text { entries }\end{array}$ & 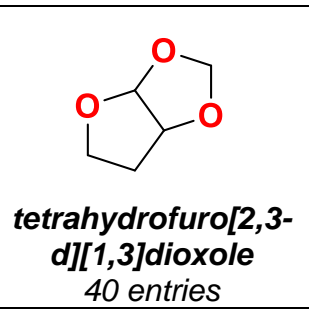 & $\begin{array}{l}\text { quinoline } \\
37 \text { entries }\end{array}$ \\
\hline $\begin{array}{c}\text { naphtalene } \\
36 \text { entries }\end{array}$ & $\begin{array}{c}\text { NH } \\
\text { morpholine } \\
32 \text { entries }\end{array}$ & $\begin{array}{l}\text { pyridine } \\
32 \text { entries }\end{array}$ & $\begin{array}{c}\text { naphtoquinone } \\
28 \text { entries }\end{array}$ & $\begin{array}{c}\text { oxalane } \\
24 \text { entries }\end{array}$ \\
\hline $\begin{array}{c}\left.\|^{\mathrm{H}}\right\rangle \\
22 \text { entries } \\
\end{array}$ & $\begin{array}{c}\text { butenolide } \\
21 \text { entries }\end{array}$ & cardenolide steroid & $\begin{array}{c}\text { indole } \\
20 \text { entries }\end{array}$ & $\begin{array}{c}\text { 1,3-dioxane } \\
17 \text { entries }\end{array}$ \\
\hline
\end{tabular}

Also, less frequent scaffolds were also counted, but distinctive fragments presented in our dataset (Table 4). The scaffolds 1,3,4-oxadiazole-2-thione, containing four heteroatoms, a spiro heterocycle, and a seven-membered nitrogen and oxygencontaining heterocycle can be highlighted. Finally, two tetrazole rings were found, being important as bioisosters for acidic groups. These results indicate a relative diversity and versatility of our dataset scaffolds.

Table 4. Distinctive chemical scaffolds presented in the BraCoLi database.

\begin{tabular}{c|c|c|c|c}
\hline $\begin{array}{c}\text { 1,3,4-oxadiazole- } \\
2 \text {-thione } \\
4 \text { entries }\end{array}$ & $\begin{array}{c}2 \mathrm{H} \text {-tetrazole } \\
3 \text { entries }\end{array}$ & $\begin{array}{c}1 \text { 1H-tetrazole } \\
2 \text { entries }\end{array}$ & $\begin{array}{c}1 \text {-oxa-4- } \\
\text { azaspiro[4.4]nonane } \\
1 \text { entry }\end{array}$ & $\begin{array}{c}\text { 1,3,5- } \\
\text { dioxazepane } \\
1 \text { entry }\end{array}$ \\
\hline
\end{tabular}




\section{CONCLUSION}

After years cataloguing this information, a total of 1,176 compounds were gathered to build the BraCoLi database. As stablished in the cheminformatic characterization, the dataset present rich chemical diversity, broad spectrum of bioactivities and drug-like potential. More than two thirds of the compounds fitted both Lipinski's Ro5 and Veber's rules. These structures can be now explored by other medicinal chemistry groups to support-their research. The dataset update is planned when novel substances are obtained to expand BraCoLi database, being a novel platform to compilate and organize information on bioactive compounds for computational studies and experimental assays.

\section{MATERIALS AND METHODS}

\section{Curation and preparation of the biological and chemical data}

The compounds were curated from prior works developed in the Laboratory of Pharmaceutical Chemistry (Faculty of Pharmacy, Federal University of Minas Gerais). Their chemical formula, molecular weight, and biological assays data were annotated. The 2D chemical structures were generated in Marvin Sketch 16.10.3 (Chemaxon, 2015). After, the structures were converted to a 3D format and had their conformation energy minimized using Discovery Studio Visualizer (BIOVIA, 2020). Also, any lacking hydrogen atoms were added to the structures. The most stable conformers were generated by OMEGA 2.5.1.460. Ionization states in physiological $\mathrm{pH}$ (7.4) were corrected using fixpka software implemented in QUACPAC 1.6.3.1 (OpenEye Scientific Software, 2016), in which the total energy was minimized using MMFF94 force field ${ }^{61}$. The 3D structures dataset is available in SDF and Mol2 file format.

\section{Drug-like profiling and cheminformatic characterization}

Molecular and physicochemical properties were calculated using PaDEL descriptor software $^{62}$. R package was used to carry out statistical analysis. Principal component analysis (PCA) was carried out using prcomp function and histogram-scatter were generated via the function scatterhist.

\section{Chemical diversity and substructures scaffolds}

The chemical substructures were generated using the function "Analyse Scaffolds" and "Plain ring systems" filter criteria in software DataWarrior 5.2.163. Applying the option "Split multiple values row", the most frequent and distinctive rings after the software counted the frequency of appearance of each substructure were manually verified. lonized conjugate acids or bases were not differentiated from the non-ionized groups. 


\section{ACKNOWLEDGMENTS}

The authors would like to thank FAPEMIG, CNPq, CAPES, and PRPq-UFMG for financial support and scholarships. Also, we would like to thank OpenEye Scientific Software for OMEGA and QUACPAC academic licenses.

\section{REFERENCES}

(1) Lin, X.; Li, X.; Lin, X. A Review on Applications of Computational Methods in Drug Screening and Design. Molecules 2020, $25 \quad$ (6), 1375. https://doi.org/10.3390/molecules25061375.

(2) Zhao, L.; Ciallella, H. L.; Aleksunes, L. M.; Zhu, H. Advancing Computer-Aided Drug Discovery (CADD) by Big Data and Data-Driven Machine Learning Modeling. Drug Discovery Today 2020, 25 (9), 1624-1638. https://doi.org/10.1016/j.drudis.2020.07.005.

(3) Ferreira, L. L. G.; Andricopulo, A. D. Chemoinformatics Approaches to Structureand Ligand-Based Drug Design. Front. Pharmacol. 2018, 9. https://doi.org/10.3389/fphar.2018.01416.

(4) Shoichet, B. K. Virtual Screening of Chemical Libraries. Nature 2004, 432 (7019), 862-865. https://doi.org/10.1038/nature03197.

(5) Brown, N.; Ertl, P.; Lewis, R.; Luksch, T.; Reker, D.; Schneider, N. Artificial Intelligence in Chemistry and Drug Design. J Comput Aided Mol Des 2020, 34 (7), 709715. https://doi.org/10.1007/s10822-020-00317-x.

(6) Nicola, G.; Liu, T.; Gilson, M. K. Public Domain Databases for Medicinal Chemistry. J. Med. Chem. 2012, 55 (16), 6987-7002. https://doi.org/10.1021/jm300501t.

(7) Bajorath, J. Extending Accessible Chemical Space for the Identification of Novel Leads. Expert Opinion on Drug Discovery 2016, 11 (9), 825-829. https://doi.org/10.1080/17460441.2016.1210126.

(8) Irwin, J. J.; Tang, K. G.; Young, J.; Dandarchuluun, C.; Wong, B. R.; Khurelbaatar, M.; Moroz, Y. S.; Mayfield, J.; Sayle, R. A. ZINC20-A Free UltralargeScale Chemical Database for Ligand Discovery. J. Chem. Inf. Model. 2020, 60 (12), 6065-6073. https://doi.org/10.1021/acs.jcim.0c00675.

(9) Kim, S.; Chen, J.; Cheng, T.; Gindulyte, A.; He, J.; He, S.; Li, Q.; Shoemaker, B. A.; Thiessen, P. A.; Yu, B.; Zaslavsky, L.; Zhang, J.; Bolton, E. E. PubChem in 2021: New Data Content and Improved Web Interfaces. Nucleic Acids Research 2021, 49 (D1), D1388-D1395. https://doi.org/10.1093/nar/gkaa971.

(10) Davies, M.; Nowotka, M.; Papadatos, G.; Dedman, N.; Gaulton, A.; Atkinson, F.; Bellis, L.; Overington, J. P. ChEMBL Web Services: Streamlining Access to Drug Discovery Data and Utilities. Nucleic Acids Research 2015, 43 (W1), W612-W620. https://doi.org/10.1093/nar/gkv352.

(11) Mendez, D.; Gaulton, A.; Bento, A. P.; Chambers, J.; De Veij, M.; Félix, E.; Magariños, M. P.; Mosquera, J. F.; Mutowo, P.; Nowotka, M.; Gordillo-Marañón, M.; 
Hunter, F.; Junco, L.; Mugumbate, G.; Rodriguez-Lopez, M.; Atkinson, F.; Bosc, N.; Radoux, C. J.; Segura-Cabrera, A.; Hersey, A.; Leach, A. R. ChEMBL: Towards Direct Deposition of Bioassay Data. Nucleic Acids Research 2019, 47 (D1), D930-D940. https://doi.org/10.1093/nar/gky1075.

(12) Gilson, M. K.; Liu, T.; Baitaluk, M.; Nicola, G.; Hwang, L.; Chong, J. BindingDB in 2015: A Public Database for Medicinal Chemistry, Computational Chemistry and Systems Pharmacology. Nucleic Acids Research 2016, 44 (D1), D1045-D1053. https://doi.org/10.1093/nar/gkv1072.

(13) Chen, C. Y.-C. TCM Database@Taiwan: The World's Largest Traditional Chinese Medicine Database for Drug Screening In Silico. PLOS ONE 2011, 6 (1), e15939. https://doi.org/10.1371/journal.pone.0015939.

(14) Wishart, D. S.; Feunang, Y. D.; Guo, A. C.; Lo, E. J.; Marcu, A.; Grant, J. R.; Sajed, T.; Johnson, D.; Li, C.; Sayeeda, Z.; Assempour, N.; lynkkaran, I.; Liu, Y.; Maciejewski, A.; Gale, N.; Wilson, A.; Chin, L.; Cummings, R.; Le, D.; Pon, A.; Knox, C.; Wilson, M. DrugBank 5.0: A Major Update to the DrugBank Database for 2018. Nucleic Acids Research 2018, 46 (D1), D1074-D1082. https://doi.org/10.1093/nar/gkx1037.

(15) Corsello, S. M.; Bittker, J. A.; Liu, Z.; Gould, J.; McCarren, P.; Hirschman, J. E.; Johnston, S. E.; Vrcic, A.; Wong, B.; Khan, M.; Asiedu, J.; Narayan, R.; Mader, C. C.; Subramanian, A.; Golub, T. R. The Drug Repurposing Hub: A next-Generation Drug Library and Information Resource. Nature Medicine 2017, 23 (4), 405-408. https://doi.org/10.1038/nm.4306.

(16) Valli, M.; dos Santos, R. N.; Figueira, L. D.; Nakajima, C. H.; Castro-Gamboa, I.; Andricopulo, A. D.; Bolzani, V. S. Development of a Natural Products Database from the Biodiversity of Brazil. J. Nat. Prod. 2013, 76 (3), 439-444. https://doi.org/10.1021/np3006875.

(17) Pilon, A. C.; Valli, M.; Dametto, A. C.; Pinto, M. E. F.; Freire, R. T.; CastroGamboa, I.; Andricopulo, A. D.; Bolzani, V. S. NuBBE DB: An Updated Database to Uncover Chemical and Biological Information from Brazilian Biodiversity. Scientific Reports 2017, 7 (1), 7215. https://doi.org/10.1038/s41598-017-07451-x.

(18) Farrell, L. J.; Lo, R.; Wanford, J. J.; Jenkins, A.; Maxwell, A.; Piddock, L. J. V. Revitalizing the Drug Pipeline: AntibioticDB, an Open Access Database to Aid Antibacterial Research and Development. J Antimicrob Chemother 2018, 73 (9), 22842297. https://doi.org/10.1093/jac/dky208.

(19) Ntie-Kang, F.; Zofou, D.; Babiaka, S. B.; Meudom, R.; Scharfe, M.; Lifongo, L. L.; Mbah, J. A.; Mbaze, L. M.; Sippl, W.; Efange, S. M. N. AfroDb: A Select Highly Potent and Diverse Natural Product Library from African Medicinal Plants. PLOS ONE 2013, 8 (10), e78085. https://doi.org/10.1371/journal.pone.0078085.

(20) Pilón-Jiménez, B. A.; Saldívar-González, F. I.; Díaz-Eufracio, B. I.; MedinaFranco, J. L. BIOFACQUIM: A Mexican Compound Database of Natural Products. Biomolecules 2019, 9 (1), 31. https://doi.org/10.3390/biom9010031. 
(21) Zhao, L.; Wang, W.; Sedykh, A.; Zhu, H. Experimental Errors in QSAR Modeling Sets: What We Can Do and What We Cannot Do. ACS Omega 2017, 2 (6), 2805-2812. https://doi.org/10.1021/acsomega.7b00274.

(22) Anuraj, N. Experimental and Computational Approaches to Improve Binding Affinity in Chemical Biology and Drug Discovery. Current Topics in Medicinal Chemistry 2020, 20 (19), 1651-1660.

(23) Martinez-Mayorga, K.; Madariaga-Mazon, A.; Medina-Franco, J. L.; Maggiora, G. The Impact of Chemoinformatics on Drug Discovery in the Pharmaceutical Industry. Expert Opinion on Drug Discovery 2020, $15 \quad$ (3), 293-306. https://doi.org/10.1080/17460441.2020.1696307.

(24) Fourches, D.; Muratov, E.; Tropsha, A. Trust, But Verify: On the Importance of Chemical Structure Curation in Cheminformatics and QSAR Modeling Research. J. Chem. Inf. Model. 2010, 50 (7), 1189-1204. https://doi.org/10.1021/ci100176x.

(25) Pereira de Sá, N.; Lino, C. I.; Fonseca, N. C.; Borelli, B. M.; Ramos, J. P.; SouzaFagundes, E. M.; Rosa, C. A.; Santos, D. A.; Barbosa de Oliveira, R.; Johann, S. Thiazole Compounds with Activity against Cryptococcus Gattii and Cryptococcus Neoformans in Vitro. European Journal of Medicinal Chemistry 2015, 102, 233-242. https://doi.org/10.1016/j.ejmech.2015.07.032.

(26) Sá, N. P. de; Lima, C. M. de; Lino, C. I.; Barbeira, P. J. S.; Baltazar, L. de M.; Santos, D. A.; Oliveira, R. B. de; Mylonakis, E.; Fuchs, B. B.; Johann, S. Heterocycle Thiazole Compounds Exhibit Antifungal Activity through Increase in the Production of Reactive Oxygen Species in the Cryptococcus Neoformans-Cryptococcus Gattii Species Complex. Antimicrobial Agents and Chemotherapy 2017, 61 (8). https://doi.org/10.1128/AAC.02700-16.

(27) Cruz, L. I. B.; Lopes, L. F. F.; De Camargo Ribeiro, F.; De Sá, N. P.; Lino, C. I.; Tharmalingam, N.; De Oliveira, R. B.; Rosa, C. A.; Mylonakis, E.; Fuchs, B. B.; Johann, S. Anti-Candida Albicans Activity of Thiazolylhydrazone Derivatives in Invertebrate and Murine Models. Journal of Fungi 2018, 4 (4), 134. https://doi.org/10.3390/jof4040134.

(28) Sá, N. P.; Pôssa, A. P.; Pilar, P.; Jaqueline, M. S. F.; Nayara, C. F.; Cleudiomar, I. L.; Lana, B. C.; Renata, B. de O.; Carlos, A. R.; Beatriz, M. B.; Eleftherios, M.; Beth, B. F.; Susana, J. Antifungal Activity Directed Toward the Cell Wall by 2Cyclohexylidenhydrazo- 4-Phenyl-Thiazole Against Candida Albicans. Infectious Disorders - Drug Targets 2019, 19 (4), 428-438.

(29) Lino, C. I.; Gonçalves de Souza, I.; Borelli, B. M.; Silvério Matos, T. T.; Santos Teixeira, I. N.; Ramos, J. P.; Maria de Souza Fagundes, E.; de Oliveira Fernandes, P.; Maltarollo, V. G.; Johann, S.; de Oliveira, R. B. Synthesis, Molecular Modeling Studies and Evaluation of Antifungal Activity of a Novel Series of Thiazole Derivatives. European Journal of Medicinal Chemistry 2018, 151, 248-260. https://doi.org/10.1016/j.ejmech.2018.03.083.

(30) Sá, N. P.; Lima, C. M.; A dos Santos, J. R.; Costa, M. C.; de Barros, P. P.; Junqueira, J. C.; Vaz, J. A.; Oliveira, R. B.; Fuchs, B. B.; Mylonakis, E.; Rosa, C. A.; Santos, D. A.; Johann, S. A Phenylthiazole Derivative Demonstrates Efficacy on 
Treatment of the Cryptococcosis \& Candidiasis in Animal Models. Future Science OA 2018, 4 (6), FSO305. https://doi.org/10.4155/fsoa-2018-0001.

(31) de Sá, N. P.; de Barros, P. P.; Junqueira, J. C.; Vaz, J. A.; de Oliveira, R. B.; Rosa, C. A.; Santos, D. A.; Johann, S. Thiazole Derivatives Act on Virulence Factors of Cryptococcus Spp. Medical Mycology 2019, $57 \quad$ (1), 84-91. https://doi.org/10.1093/mmy/myx158.

(32) Sá, N. P. de; Barros, P. P. de; Junqueira, J. C.; Valério, A. D.; Lino, C. I.; Oliveira, R. B. de; Rosa, C. A.; Johann, S. Antivirulence Activity and in Vivo Efficacy of a Thiazole Derivative against Candidiasis. Journal of Medical Mycology 2021, 31 (2), 101134. https://doi.org/10.1016/j.mycmed.2021.101134.

(33) Franco, P. H. C.; Braga, S. F. P.; Oliveira, R. B. de; César, I. C. Purity Determination of a New Antifungal Drug Candidate Using Quantitative 1H NMR Spectroscopy: Method Validation and Comparison of Calibration Approaches. Magnetic Resonance in Chemistry 2020, 58 (1), 97-105. https://doi.org/10.1002/mrc.4936.

(34) Silva, I. R.; Braga, A. V.; Gloria, M. B. de A.; Machado, R. de R.; César, I. C.; Oliveira, R. B. Preclinical Pharmacokinetic Study of a New Thiazolyl Hydrazone Derivative with Antifungal Activity in Mice Plasma by LC-MS/MS. Journal of Chromatography B 2020, 1149, 122180. https://doi.org/10.1016/j.jchromb.2020.122180.

(35) Tonholo, D. R.; Maltarollo, V. G.; Kronenberger, T.; Silva, I. R.; Azevedo, P. O.; Oliveira, R. B.; Souza, L. C. R.; Tagliati, C. A. Preclinical Toxicity of Innovative Molecules: In Vitro, in Vivo and Metabolism Prediction. Chemico-Biological Interactions 2020, 315, 108896. https://doi.org/10.1016/j.cbi.2019.108896.

(36) Franco, P. H. C.; Vieira, J. G.; Ramos, C. A. de O.; Johann, S.; Oliveira, R. B. de; César, I. C. Stability-Indicating Method for the Novel Antifungal Compound RI76: Characterization and in Vitro Antifungal Activity of Its Active Degradation Product. Biomedical Chromatography 2021, 35 (3), e5014. https://doi.org/10.1002/bmc.5014.

(37) Silva, I. R.; Kronenberger, T.; Gomes, E. C. L.; César, I. C.; Oliveira, R. B.; Maltarollo, V. G. Improving the Solubility of an Antifungal Thiazolyl Hydrazone Derivative by Cyclodextrin Complexation. European Journal of Pharmaceutical Sciences 2021, 156, 105575. https://doi.org/10.1016/j.ejps.2020.105575.

(38) Asse Junior, L. R.; Kronenberger, T.; Magalhães Serafim, M. S.; Sousa, Y. V.; Franco, I. D.; Valli, M.; Silva Bolzani, V. da; Monteiro, G. C.; Bruno Prates, J. L.; Kroon, E. G.; Fernandes Mota, B. E.; Santos Ferreira, D. dos; de Oliveira, R. B.; Maltarollo, V. G. Virtual Screening of Antibacterial Compounds by Similarity Search of Enoyl-ACP Reductase (Fabl) Inhibitors. Future Medicinal Chemistry 2019, 12 (1), 51-68. https://doi.org/10.4155/fmc-2019-0158.

(39) Serafim, M. S. M.; Lavorato, S. N.; Kronenberger, T.; Sousa, Y. V.; Oliveira, G. P.; Santos, S. G. dos; Kroon, E. G.; Maltarollo, V. G.; Alves, R. J.; Mota, B. E. F. Antibacterial Activity of Synthetic 1,3-Bis(Aryloxy)Propan-2-Amines against GramPositive Bacteria. MicrobiologyOpen 2019, $8 \quad$ (11), $\quad$ e814. https://doi.org/10.1002/mbo3.814. 
(40) Lana, D. F. D.; Lavorato, S. N.; Giuliani, L. M.; Cruz, L.; Lopes, W.; Vainstein, M. H.; Fontana, I. C.; Zimmer, A. R.; Freitas, M. de A.; Andrade, S. F. de; Alves, R. J.; Fuentefria, A. M. Discovery of a Novel and Selective Fungicide That Targets Fungal Cell Wall to Treat Dermatomycoses: 1,3-Bis(3,4-Dichlorophenoxy)Propan-2-Aminium Chloride. Mycoses 2020, 63 (2), 197-211. https://doi.org/10.1111/myc.13027.

(41) Lavorato, S. N.; Duarte, M. C.; Lage, D. P.; Tavares, C. A. P.; Coelho, E. A. F.; Alves, R. J. 1,3-Bis(Aryloxy)Propan-2-Ols as Potential Antileishmanial Agents. Chemical Biology \& Drug Design 2017, 90 (5), 981-986. https://doi.org/10.1111/cbdd.13024.

(42) Lavorato, S. N.; Duarte, M. C.; Lage, D. P.; Tavares, C. A. P.; Coelho, E. A. F.; Alves, R. J. Synthesis and Antileishmanial Activity of 1,3-Bis(Aryloxy)Propan-2-Amines. Med Chem Res 2017, 26 (5), 1052-1072. https://doi.org/10.1007/s00044-017-1805-1.

(43) Lavorato, S. N.; Sales Júnior, P. A.; Murta, S. M. F.; Romanha, A. J.; Alves/, R. J.; Lavorato, S. N.; Sales Júnior, P. A.; Murta, S. M. F.; Romanha, A. J.; Alves/, R. J. In Vitro Activity of 1,3-Bisaryloxypropanamines against Trypanosoma Cruzi-Infected L929 Cultures. Memórias do Instituto Oswaldo Cruz 2015, 110 (4), 566-568. https://doi.org/10.1590/0074-02760150007.

(44) Dalla Lana, D. F.; Kaminski, T. F. A.; Lavorato, S. N.; Merkel, S.; Zanette, R. A.; da Rosa, P. D.; Staudt, K. J.; de Araújo, B. V.; da Costa, B.; Quatrin, P. M.; Bazana, L. C. G.; Ferreira, F. A.; Caurio, C. F. B.; de Andrade, S. F.; Alves, R. J.; Fuentefria, A. M. In Vitro Pharmacokinetics/Pharmacodynamics Modeling and Efficacy against Systemic Candidiasis in Drosophila Melanogaster of a Bisaryloxypropanamine Derivative. Medical Mycology 2021, 59 (1), 58-66. https://doi.org/10.1093/mmy/myaa030.

(45) Coelho, E. A. F.; Alves, R. J.; Romanha, A. J.; Lavorato, S. N. Diarilaminas, composições farmacêuticas contendo as diarilaminas e usos. B.R. Patent BR1020140290788, November 21, 2014.

(46) Shultz, M. D. Two Decades under the Influence of the Rule of Five and the Changing Properties of Approved Oral Drugs. J. Med. Chem. 2019, 62 (4), 1701-1714. https://doi.org/10.1021/acs.jmedchem.8b00686.

(47) Lipinski, C. A.; Lombardo, F.; Dominy, B. W.; Feeney, P. J. Experimental and Computational Approaches to Estimate Solubility and Permeability in Drug Discovery and Development Settings1PII of Original Article: S0169-409X(96)00423-1. The Article Was Originally Published in Advanced Drug Delivery Reviews 23 (1997) 3-25.1. Advanced Drug Delivery Reviews 2001, 46 (1), 3-26. https://doi.org/10.1016/S0169409X(00)00129-0.

(48) Veber, D. F.; Johnson, S. R.; Cheng, H.-Y.; Smith, B. R.; Ward, K. W.; Kopple, K. D. Molecular Properties That Influence the Oral Bioavailability of Drug Candidates. J. Med. Chem. 2002, 45 (12), 2615-2623. https://doi.org/10.1021/jm020017n.

(49) Ghose, A. K.; Viswanadhan, V. N.; Wendoloski, J. J. A Knowledge-Based Approach in Designing Combinatorial or Medicinal Chemistry Libraries for Drug Discovery. 1. A Qualitative and Quantitative Characterization of Known Drug Databases. J. Comb. Chem. 1999, 1 (1), 55-68. https://doi.org/10.1021/cc9800071. 
(50) Muegge, I.; Heald, S. L.; Brittelli, D. Simple Selection Criteria for Drug-like Chemical Matter. J. Med. Chem. 2001, 44 (12), 1841-1846. https://doi.org/10.1021/jm015507e.

(51) Lipinski, C. A. Lead- and Drug-like Compounds: The Rule-of-Five Revolution. Drug Discovery Today: Technologies 2004, 1 (4), 337-341. https://doi.org/10.1016/j.ddtec.2004.11.007.

(52) Pathania, S.; Singh, P. K. Analyzing FDA-Approved Drugs for Compliance of Pharmacokinetic Principles: Should There Be a Critical Screening Parameter in Drug Designing Protocols? Expert Opinion on Drug Metabolism \& Toxicology 2020, 0 (0), 14. https://doi.org/10.1080/17425255.2021.1865309.

(53) Varma, M. V. S.; Obach, R. S.; Rotter, C.; Miller, H. R.; Chang, G.; Steyn, S. J.; El-Kattan, A.; Troutman, M. D. Physicochemical Space for Optimum Oral Bioavailability: Contribution of Human Intestinal Absorption and First-Pass Elimination. J. Med. Chem. 2010, 53 (3), 1098-1108. https://doi.org/10.1021/jm901371v.

(54) Giordanetto, F.; Kihlberg, J. Macrocyclic Drugs and Clinical Candidates: What Can Medicinal Chemists Learn from Their Properties? J. Med. Chem. 2014, 57 (2), 278295. https://doi.org/10.1021/jm400887j.

(55) Lipinski, C. A. Rule of Five in 2015 and beyond: Target and Ligand Structural Limitations, Ligand Chemistry Structure and Drug Discovery Project Decisions. Advanced Drug Delivery Reviews 2016, 101, 34-41. https://doi.org/10.1016/j.addr.2016.04.029.

(56) Furukawa, A.; Schwochert, J.; Pye, C. R.; Asano, D.; Edmondson, Q. D.; Turmon, A. C.; Klein, V. G.; Ono, S.; Okada, O.; Lokey, R. S. Drug-Like Properties in Macrocycles above MW 1000: Backbone Rigidity versus Side-Chain Lipophilicity. Angewandte Chemie 2020, 132 (48), 21755-21761. https://doi.org/10.1002/ange.202004550.

(57) Protti, Í. F.; Rodrigues, D. R.; Fonseca, S. K.; Alves, R. J.; Oliveira, R. B. de; Maltarollo, V. G. Do Drug-Likeness Rules Apply to Oral Prodrugs? ChemMedChem 2021, n/a (n/a). https://doi.org/10.1002/cmdc.202000805.

(58) Jampilek, J. Heterocycles in Medicinal Chemistry. Molecules 2019, 24 (21), 3839. https://doi.org/10.3390/molecules24213839.

(59) Karuppiah, V.; Sun, W.; Li, Z. Chapter 13 - Natural Products of Actinobacteria Derived from Marine Organisms. In Studies in Natural Products Chemistry; Atta-urRahman, Ed.; Elsevier, 2016; Vol. 48, pp 417-446. https://doi.org/10.1016/B978-0-44463602-7.00013-8.

(60) Hawkins, P. C. D.; Skillman, A. G.; Warren, G. L.; Ellingson, B. A.; Stahl, M. T. Conformer Generation with OMEGA: Algorithm and Validation Using High Quality Structures from the Protein Databank and Cambridge Structural Database. J. Chem. Inf. Model. 2010, 50 (4), 572-584. https://doi.org/10.1021/ci100031x. 
(61) Halgren, T. A. MMFF VI. MMFF94s Option for Energy Minimization Studies. Journal of Computational Chemistry 1999, 20 (7), 720-729. https://doi.org/10.1002/(SICI)1096-987X(199905)20:7<720::AID-JCC7>3.0.CO;2-X.

(62) Yap, C. W. PaDEL-Descriptor: An Open Source Software to Calculate Molecular Descriptors and Fingerprints. Journal of Computational Chemistry 2011, 32 (7), 14661474. https://doi.org/10.1002/jcc.21707.

(63) Sander, T.; Freyss, J.; von Korff, M.; Rufener, C. DataWarrior: An Open-Source Program For Chemistry Aware Data Visualization And Analysis. J. Chem. Inf. Model. 2015, 55 (2), 460-473. https://doi.org/10.1021/ci500588j. 